semiconducting TMDCs emit at a wavelength from 600 to $700 \mathrm{~nm}$, it is possible to extend the emission wavelength to the telecommunication range (1.3 and $1.55 \mu \mathrm{m})$ and possibly to the mid-infrared, using the recently rediscovered black phosphorus $^{12-15}$. This emerging $2 \mathrm{D}$ material has a widely tunable electronic bandgap from 0.3 to about $2 \mathrm{eV}$ (bulk to monolayer), covering a broad wavelength range. It might also be possible to construct doubleheterostructure LEDs by sandwiching the narrow-bandgap black phosphorus between two large-bandgap TMDCs with opposite doping polarity, allowing for the confinement of light and carriers simultaneously ${ }^{1}$. Given the large variety of available $2 \mathrm{D}$ materials and the great flexibility in combining them, these heterostructures may not only compete as light emitters in the visible spectral range as shown by Novoselov and collaborators, but they could also trigger the development of applications in less explored electromagnetic spectral ranges such as in terahertz and mid-infrared.

Xiaomu Wang and Fengnian Xia are in the Department of Electrical Engineering, Yale University, 15 Prospect Street, New Haven, Connecticut 06511, USA.

e-mail: fengnian.xia@yale.edu
References

1. Alferov, Z. IEEE J. Select. Top. Quantum Electron. 6, 832-840 (2000).

2. Kroemer, H. Proc. IEEE 70, 13-25 (1982)

3. Yablonovitch, E. \& Kane, E. O. J. Lightwave Technol. 6, 1292-1299 (1988).

4. Withers, F. et al. Nature Mater. 14, 301-306 (2015).

5. Britnell, L. et al. Science 340, 1311-1314 (2013).

6. Dean, C. R. et al. Nature Nanotech. 5, 722-726 (2010).

Xu, X., Yao, W., Xiao, D. \& Heinz, T. F. Nature Phys. 10, 343-350 (2014).

8. Reineke, S. et al. Nature 459, 234-238 (2009).

9. Novoselov, K. S. et al. Proc. Natl Acad. Sci. USA 102, 10451-10453 (2005).

10. Gong, Y. et al. Nature Mater. 13, 1135-1142 (2014).

11. Lee, Y.-H. et al. Nano Lett. 13, 1852-1857 (2013).

12. Li, L. et al. Nature Nanotech. 9, 372-377 (2013).

13. Xia, F., Wang, H. \& Jia, Y. Nature Commun. 5, 4458 (2014).

14. Liu, H. et al. ACS Nano 8, 4033-4041 (2014).

15. Koenig, S. P. et al. Appl. Phys. Lett. 104, 103106 (2014).

Published online: 2 February 2015

\title{
A GRAPHENE EXPLOSION
}

If all has gone according to plan, by the time this piece has gone to press Manchester will have been showered with meteorites. An exhibition at the University of Manchester's Whitworth art gallery by the artist Cornelia Parker is due to be opened on 13 February with a firework display in which pieces of meteoritic iron will be shot into the sky.

The pyrotechnics won't be started simply by lighting the blue touchpaper. The conflagration will be triggered by a humidity sensor, switched by the breath of physicist Kostya Novoselov, whose work on graphene at Manchester University with Andre Geim won them both the 2010 Nobel Prize in Physics. The sensor is itself made from graphene, obtained from flakes of graphite taken from drawings by William Blake, J. M. W. Turner, John Constable and Pablo Picasso as well as from a pencilwritten letter by Ernest Rutherford, whose pioneering work on atomic structure was conducted at Manchester.

That graphene (oxide) can serve as an ultrasensitive humidity sensor was reported by Bi et al. ${ }^{1}$, and such devices have since been refined to give a very rapid response ${ }^{2}$. Adsorption of water onto the graphene oxide film alters its capacitance, providing a sensing mechanism when the film acts as an insulating layer between two electrodes. These sensors are now being developed by Nokia. The devices used for Parker's show were provided by Novoselov's group after the two of them were introduced by the Whitworth's director Maria Balshaw. Novoselov extracted the graphite samples from artworks owned by the gallery, using tweezers under careful supervision.

"I love the idea of working on a nano level", Parker has said. "The idea of graphene, something so small, being a catalyst." She is not simply talking figuratively: doped graphene has indeed been explored as an electrocatalyst for fuel cells $s^{3,4}$.

Parker has a strong interest in interacting with science and scientists. In 1997 she produced a series of works for Nature examining unexpected objects in a quasiscientific context ${ }^{5}$. Much of her work focuses on connotations of materiality: associations arising from what things are made of and the incongruity of materials repurposed or set out of place. Her installation Thirty Pieces of Silver (1988-1999) used an assortment of silver objects such as instruments and cutlery flattened by a steamroller. She has worked with the red crepe paper left over from the manufacture of Remembrance Day poppies, with lead bullets and gold teeth extruded into wire, and with her own blood. Perhaps even her most famous work Cold Dark Matter: An Exploded View (1991) - the reconvened fragments of an exploded shed - was stimulated as much by the allure of the 'matter' as by the cosmological allusion.

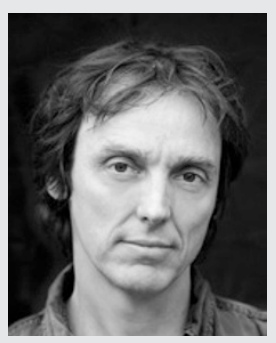

PHILIP BALL

"I like the garden shed aspect of scientists", she has said, "the way they like playing about with materials." Unusually for an artist, she seems more excited by the messy, ad hoc aspects of practical science - the kind of experimentation for which Rutherford was so renowned - than by grand, abstract ideas. The fact that Novoselov and Geim made some of their graphene samples using Scotch tape to strip away layers from graphite no doubt added to its appeal.

Parker also recognizes that materials tell stories. There's a good chance that both Blake and Rutherford would have used graphite from the plumbago mines of Borrowdale in Cumbria, about 80 miles north of Manchester and the source of the Keswick pencil industry. So even Parker's graphene might be locally sourced.

\section{References}

1. Bi, H. et al. Sci. Rep. 3, 2714 (2013).

2. Borini, S. et al. ACS Nano 7, 11166-11173 (2013).

3. Geng, D. et al. Energy Environ. Sci. 4, 760-764 (2011).

4. Fei, H. et al. ACS Nano 8, 10837-10843 (2014).

5. Nature 389,$335 ; 548 ; 668$ (1997). 